\title{
Effect of p38 MAPK inhibition on corticosteroid suppression of cytokine release in severe asthma
}

\author{
P. Bhavsar*, N. Khorasani*, M. Hew*, M. Johnson" and K.F. Chung*
}

ABSTRACT: Patients with severe asthma respond less well to corticosteroids than those with non-severe asthma. Increased p38 mitogen-activated protein kinase (MAPK) activation in alveolar macrophages (AMs) from severe asthma patients has been associated with a reduced inhibition of cytokine release by dexamethasone.

We determined whether p38 MAPK inhibitors would modulate corticosteroid suppression of cytokine release from AMs and peripheral blood mononuclear cells (PBMCs).

PBMCs were isolated from venous blood and AMs by bronchoalveolar lavage in severe and non-severe asthma patients. PBMCs and AMs were exposed to lipopolysaccharide (LPS) with and without the p38 MAPK inhibitor, SD282, or dexamethasone. We determined the concentrationdependent effects of another p38 MAPK inhibitor, GW-A, on dexamethasone-induced inhibition of interleukin (IL)-8 release from PBMCs. Cytokines were assayed using an ELISA-based method.

SD282 $\left(10^{-7} \mathrm{M}\right)$, with dexamethasone $\left(10^{-6} \mathrm{M}\right)$, caused a greater inhibition of release of IL-1ß, IL-6, macrophage inflammatory protein-1 $\alpha$ and IL-10, than with dexamethasone alone in AMs from severe and non-severe asthma. At $10^{-9}$ and $10^{-10} \mathrm{M}$, GW-A, that had no direct effects, increased the inhibitory activity of dexamethasone $\left(10^{-8}\right.$ and $\left.10^{-6} \mathrm{M}\right)$ on LPS-induced IL-8 release in PBMCs from severe asthma.

Corticosteroid insensitivity in severe asthma patients may be improved by inhibitors of p38 MAPK.

KEYWORDS: Alveolar macrophages, corticosteroid-resistant asthma, cytokines, p38 mitogenactivated protein kinase, severe asthma

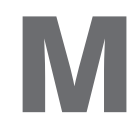
ost asthma patients are well controlled on inhaled corticosteroid therapy, but a small proportion experience continuing symptoms. These patients, labelled as having severe asthma, consume a more significant proportion of medical resources in terms of drugs, admissions to hospital or use of emergency services, and time off work or school [1]. Definitions and the clinical features of recently described cohorts attest to the persistent loss of control of asthma despite the optimal use of asthma medication. Such patients demonstrate a poor response to the therapeutic effects of corticosteroids. Peripheral blood mononuclear cells (PBMCs) and alveolar macrophages (AMs) from patients with severe asthma are less sensitive to inhibition by dexamethasone in terms of the stimulated release of pro-inflammatory cytokines, when compared with cells from wellcontrolled non-severe asthma patients $[2,3]$.

The mechanisms underlying this poor suppressive response to corticosteroids in severe asthma are unclear but many have been proposed from in vitro studies in cells [4]. We observed that AMs from patients with severe asthma demonstrated a greater degree of activation of p38 mitogenactivated protein kinase (MAPK) [2]. p38 MAPK is a family of serine-threonine kinase that act on a variety of substrates including transcription factors, such as nuclear factor (NF)- $\mathrm{kB}$ and activator protein-1 and has been implicated in inflammation, cell proliferation and cell death relevant to asthma pathophysiology [5]. We hypothesised that activation of p38 MAPK could be linked to the reduced inhibition of cytokine release by corticosteroids since part of the action of corticosteroids may relate to inhibition of MAPK activation. In addition, p38 MAPK activation has been previously shown to induce corticosteroid insensitivity in PBMCs through phosphorylation of the glucocorticoid receptor [6], indicating one potential mechanism of corticosteroid insensitivity.

Selective inhibitors of p38 MAPK, mainly the $\alpha$ isoform, have been developed. In seeking to implicate a role for p38 MAPK activation in

\section{AFFILIATIONS}

* Section of Airways Disease, National Heart \& Lung Institute, Imperial College \& Royal Brompton and Harefield NHS Trust Hospital, London, and

\#GlaxoSmithKline, Uxbridge, UK.

CORRESPONDENCE

K.F. Chung

National Heart \& Lung Institute

Dovehouse St

London SW3 6LY

UK

E-mail: f.chung@imperial.ac.uk

\section{Received:}

May 012009

Accepted after revision:

Sept 302009

First published online:

Oct 192009 
corticosteroid sensitivity, we examined whether inhibitors of p38 MAPK could improve the ability of dexamethasone in suppressing cytokine release in AMs and PBMCs from patients with severe asthma.

\section{METHODS}

\section{Study participants}

Asthma patients with either bronchodilator responses to albuterol of $\geqslant 12 \%$ of baseline forced expiratory volume in $1 \mathrm{~s}$ (FEV1) or with a provocative concentration of methacholine causing a $20 \%$ fall in FEV1 (PC20) of $<16 \mathrm{mg} \cdot \mathrm{mL}^{-1}$ (table 1 ) were recruited from the Royal Brompton Severe Asthma Clinic (London, UK). Current and ex-smokers of $>5$ pack-yrs were excluded. "Severe" asthmatics were defined according to the American Thoracic Society criteria [7]. "Non-severe" asthmatic patients used 0$2,000 \mu \mathrm{g}$ of inhaled beclomethasone-equivalent per day with control of their asthma. The protocols were approved by the local ethics committee (the Royal Brompton, Harefield and National Heart and Lung Institute Ethics Committee, London UK). All volunteers gave written informed consent.

\section{Isolation of alveolar macrophages}

Fibreoptic bronchoscopy was performed with intravenous midazolam and alfentanyl. Bronchoalveolar lavage was performed in the right middle lobe with $0.9 \% \mathrm{NaCl}$ solution. Macrophages $\left(5 \times 10^{5} \cdot\right.$ well $\left.^{-1}\right)$ were purified by adhesion to plastic wells for $4 \mathrm{~h}$ and then exposed for $18 \mathrm{~h}$ to lipopolysaccharide (LPS; $10 \mu \mathrm{g} \cdot \mathrm{mL}^{-1}$ ) in the presence or absence of dexamethasone $\left(10^{-6} \mathrm{M}\right)$ or of a selective p38 MAPK inhibitor, SD282 $\left(10^{-7} \mathrm{M}\right.$; Scios Inc, Freemont, CA, USA) [8, 9] or both.

\section{Isolation of PBMCs}

Venous blood $(80 \mathrm{~mL})$ was diluted 1:1 with Hank's buffered saline solution and layered on Ficoll-Hypaque-Plus. Following centrifugation, PBMCs were re-suspended in culture media, plated $\left(7.5 \times 10^{5}\right.$ cells $\cdot$ well $\left.^{-1}\right)$ and stimulated with LPS $\left(10 \mu \mathrm{g} \cdot \mathrm{mL}^{-1}\right)$ with or without dexamethasone $\left(10^{-6} \mathrm{M}\right)$ or SD282 $\left(10^{-7} \mathrm{M}\right)$ or both. Supernatants at $18 \mathrm{~h}$ were analysed for macrophage inflammatory protein (MIP)- $1 \alpha$, interleukin (IL)-1 $\beta$, IL-6 and IL-10.

LPS-stimulated PBMCs were also used to examine the effect of GW-A $\left(10^{-12}-10^{-6} \mathrm{M}\right)$, a p38 MAPK inhibitor from GlaxoSmithKline (Stevenage, UK), or dexamethasone $\left(10^{-12}\right.$ $10^{-6} \mathrm{M}$ ) or of the combination of GW-A and dexamethasone on IL-8 release.

\section{p38 MAPK phosphorylation}

To determine p38 MAPK activity, PBMCs were stimulated with LPS overnight in the presence or absence of dexamethasone $\left(10^{-8} \mathrm{M}\right)$ and/or GW-A $\left(10^{-9} \mathrm{M}\right)$. The contents of each well were stored in Beadlyte cell lysis buffer B (Beadlyte ${ }^{\circledR}$, Upstate Technology, NY, USA) at $-70^{\circ} \mathrm{C}$ for later assay for phosphorylated and total p38 MAPK using microsphere beads coated with antibodies to P-p38 and total p38 using the Beadlyte ${ }^{\circledR}$ protocol.

\section{Measurement of cytokine release}

The cytokines MIP- $1 \alpha$, IL- $1 \beta$, IL- 6 and IL-10 were assayed simultaneously using microsphere beads (Beadlyte ${ }^{\circledR}$ ) coated with capture antibodies. Biotinylated reporter antibodies were used to bind the microsphere bead-cytokine complexes. Finally, a fluorophore, streptavidin-phycoerythrin was added to bind the biotinylated reporter, and the fluorescent signal measured in a laser spectrophotometer (Luminex Corporation, Austin, TX, USA). Microsphere beads for each cytokine emitted a unique ratio of two other fluorophores. IL-8 was measured using ELISA.

\section{TABLE 1 Characteristics of non-severe and severe asthma subjects in the SD282 and GW-A study}

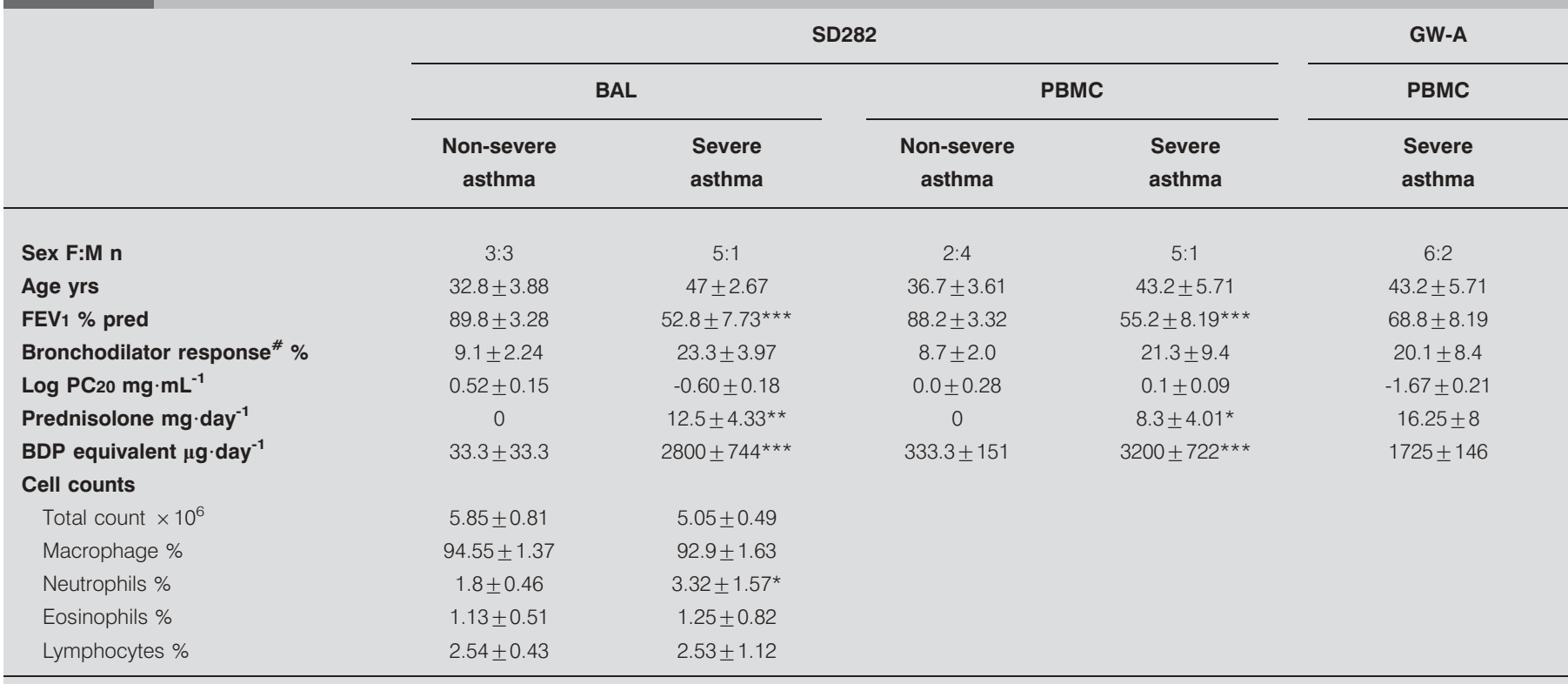

Data are presented as mean \pm SEM, unless otherwise stated. BAL: bronchoalveolar lavage; PBMC: peripheral blood mononuclear cells; F: female; M: male; FEV1: forced expiratory volume in $1 \mathrm{~s}$; \% pred: \% predicted; PC20: provocative concentration of methacholine causing a $20 \%$ fall in FEV 1 ; BDP: beclomethasone dipropionate. \#: measured as percentage increase over baseline FEV1 after $400 \mu \mathrm{g}$ albuterol aerosol; *: $p<0.05$; ${ }^{* *}: p \leqslant 0.01$; ***: $p \leqslant 0.001$ compared with non-severe asthma. 


\section{Data analysis}

Results were expressed as mean \pm SEM. Cytokine release induced by LPS with or without dexamethasone or p38 MAPK inhibitor was calculated by subtraction of baseline release. The release of each cytokine following dexamethasone and LPS combined was calculated as a percentage of cytokine release following LPS stimulation alone. Corticosteroid sensitivity between severe asthma and non-severe asthma patients was compared using the Mann-Whitney U-test. The effect of SD282 on the suppressive effect of dexamethasone was analysed by Wilcoxon paired t-test. Concentration-dependent responses were examined using one-way ANOVA (KruskalWallis test) followed by a Dunn's Multiple Comparison test. A p-value of $<0.05$ was considered significant.

\section{RESULTS}

\section{Corticosteroid insensitivity in AMs and PBMCs}

Baseline and LPS-stimulated release of IL-1 $\beta$, IL-6, MIP- $1 \alpha$ and IL-10 from both AMs and PBMCs did not significantly differ between patients with severe asthma and patients with nonsevere asthma. There was less inhibition of cytokine release from AMs in the severe asthma group compared with that in the non-severe group for IL- $1 \beta$, IL- 6 and MIP- $1 \alpha$, with the percentage of cytokine release after LPS and dexamethasone to that after LPS alone being $71 \pm 8$ versus $26 \pm 7(\mathrm{p}<0.01), 52 \pm 9$ versus $20 \pm 5 \quad(\mathrm{p}<0.05)$, and $70 \pm 9$ versus $28 \pm 7 \quad(\mathrm{p}<0.01)$, respectively. There was no significant difference regarding IL-10 (12 \pm 4 versus $30 \pm 10)$ (fig. 1a).

For PBMCs, there was a non-significant trend for less suppression by dexamethasone in patients with severe asthma compared with non-severe asthma: IL-1 $\beta$ (46 \pm 19 versus $27 \pm 8)$; IL-6 (35 \pm 8 versus $22 \pm 6)$; MIP- $1 \alpha$ ( $48 \pm 14$ versus $45 \pm 19)$; IL-10 $(68 \pm 10$ versus $42 \pm 9)$ (fig. $1 b)$.

\section{Effect of SD282 on dexamethasone inhibition of cytokine release}

In AMs from non-severe asthma, the suppressive effect of dexamethasone was relatively greater than that of SD282 and there was more inhibition of IL- 6 and MIP-1 $\alpha$ with the combination, with a trend towards greater suppression for IL-1 $\beta$ (fig. 2a). In AMs from severe asthma, SD282 alone caused only a small degree of suppression of LPS-induced IL-1 $\beta$, IL-6, MIP-1 $\alpha$ and IL-10 release, being similar in magnitude to that seen with dexamethasone alone (fig. 2b). Combined SD282 and dexamethasone caused a greater inhibition of cytokine release compared with dexamethasone alone for the four cytokines.

In PBMCs, the inhibitory effect of SD282 was greater than that observed in AMs. Although there were significant differences between the effect of dexamethasone and that of dexamethasone and SD282 for the release of all four cytokines, with less effect on the release of MIP- $1 \alpha$ from PBMCs of non-severe asthma patients, there was no evidence of additivity in the presence of both dexamethasone and SD282 (fig. 3a). Similar observations were made in PBMCs from severe asthma patients (fig. 3b).

\section{Effect of dexamethasone and GW-A on p38 activation and IL-8 release from PBMCs}

To determine whether GW-A $\left(10^{-9} \mathrm{M}\right)$ demonstrates inhibitory effects on p38 MAPK activity, the ratio of phosphorylated p38 to total p38 was measured at $24 \mathrm{~h}$. GW-A $\left(10^{-9} \mathrm{M}\right)$ alone or in combination with dexamethasone $\left(10^{-8} \mathrm{M}\right)$ attenuated p38 activity induced by LPS stimulation (fig. 4).

In order to determine whether there was additivity or synergy between dexamethasone and a p38 MAPK inhibitor, we measured the inhibitory effect of dexamethasone and GW-A alone on LPS-induced IL-8 release from PBMCs from severe asthmatics. A maximal inhibition of $51.2 \pm 4.01 \%$ release was achieved at $10^{-6} \mathrm{M}$ dexamethasone with a median inhibitory concentration (IC50) of $3.9 \times 10^{-7} \mathrm{M}$, while GW-A caused maximal suppression of $51.6 \pm 7.1 \%$ at $10^{-6} \mathrm{M}$ with an IC50 of $3.7 \times 10^{-7} \mathrm{M}$.

The effect of dexamethasone at $10^{-6} \mathrm{M}$ (fig. 5a) in suppressing IL-8 release was improved in the presence of GW-A $\left(10^{-10}\right.$ $\left.10^{-6} \mathrm{M}\right)(\mathrm{p}<0.0001$, one-way ANOVA) with a maximal suppression of $89.6 \pm 2.6 \%$ with GW-A at $10^{-6}$ and $10^{-7} \mathrm{M}$, compared with $51.9 \pm 4.0 \%$ suppression with dexamethasone alone $(\mathrm{p}<0.001)$. With GW-A $10^{-9} \mathrm{M}$ and $10^{-10} \mathrm{M}$, which alone had an inhibitory effect of $<3 \%$, IL-8 suppression by dexamethasone $\left(10^{-6} \mathrm{M}\right)$ was increased to $76.8 \pm 3.5 \%$ $(p<0.05)$ and $70.1 \pm 2.0 \%(p<0.01)$, respectively (fig. $5 b)$.
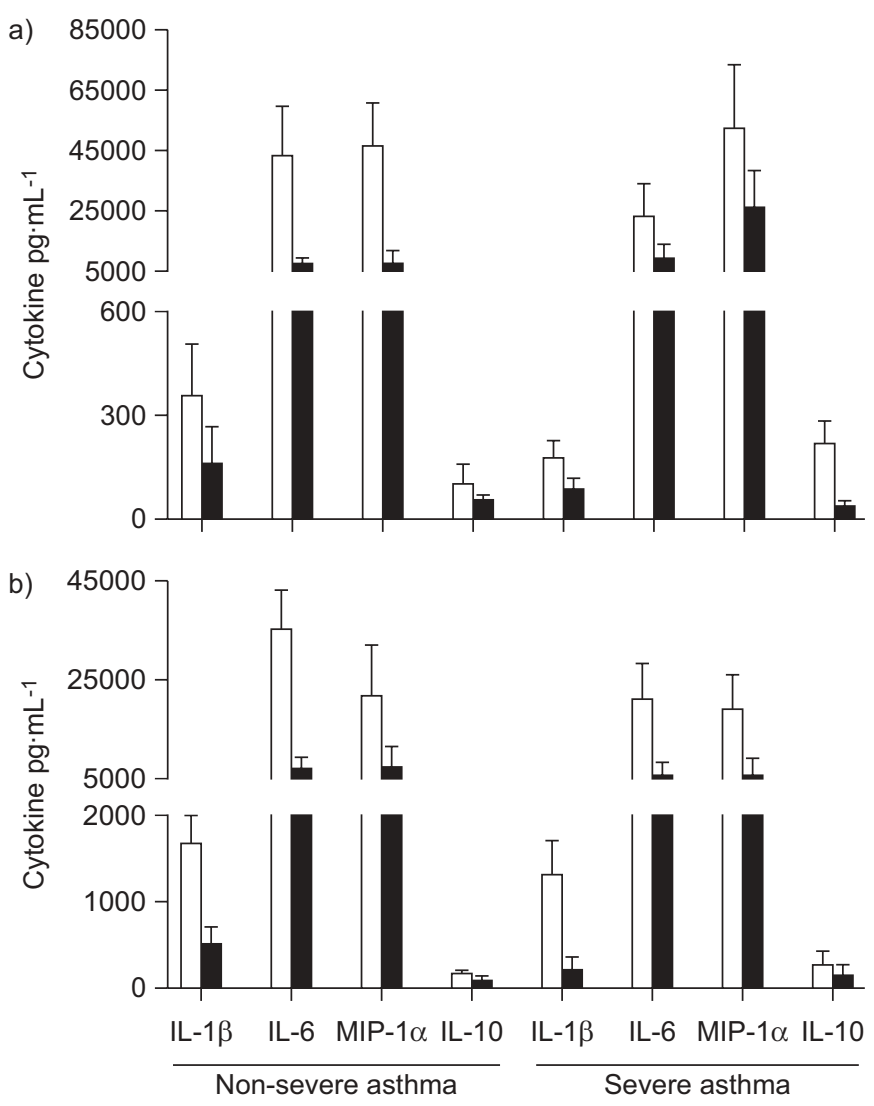

FIGURE 1. Concentrations of cytokines in cell culture supernatants of a) alveolar macrophage and b) peripheral blood mononuclear cells from patients with non-severe and severe asthma, stimulated with lipopolysaccharide $\left(10 \mu \mathrm{g} \cdot \mathrm{mL}^{-1}\right)$ in the presence $(\boldsymbol{\square})$ and absence $(\square)$ of dexamethasone $\left(10^{-6} \mathrm{M}\right)$. There were no significant differences in stimulated levels of interleukin (IL)-1 $\beta$, IL-6, macrophage inflammatory protein (MIP)- $1 \alpha$ and IL-10 between patients with severe and nonsevere asthma. There was a significant decrease in release of cytokines in the presence of dexamethasone for both cell types and both patient groups. 

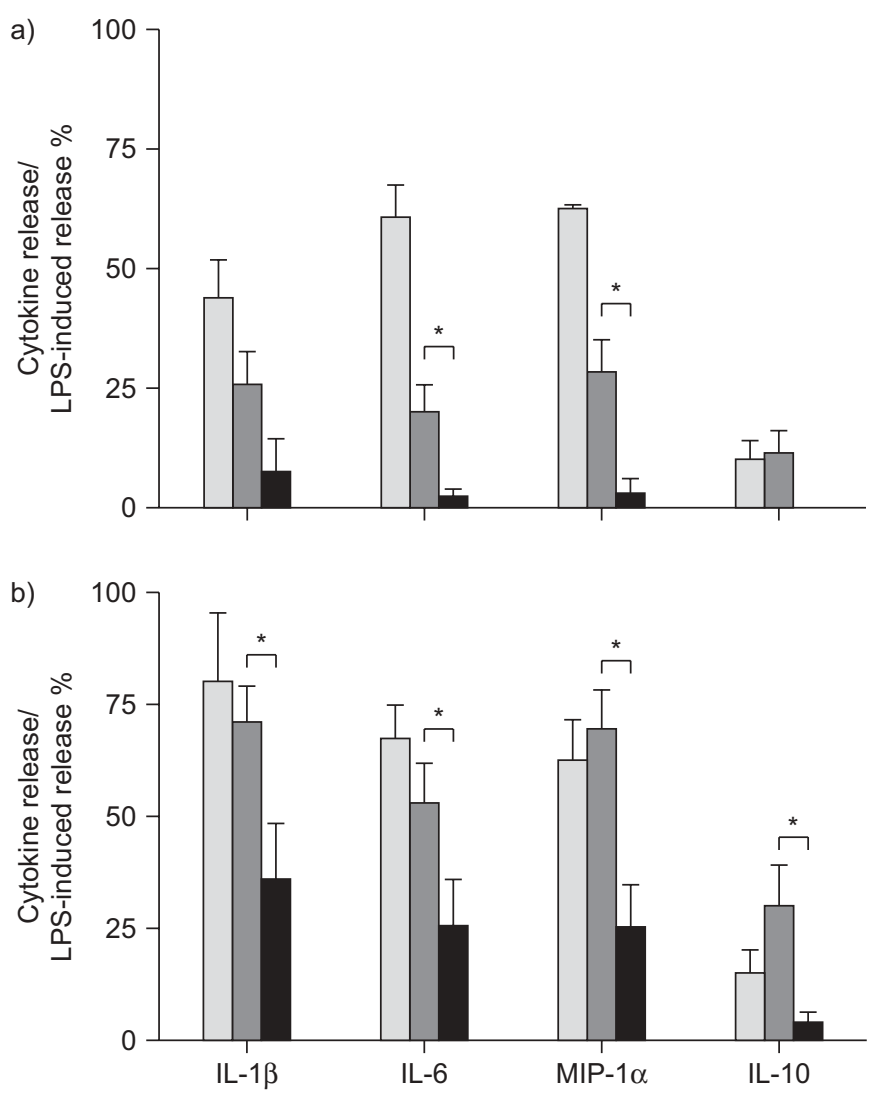

FIGURE 2. Inhibition of lipopolysaccharide (LPS)-induced cytokine (interleukin (IL)-1 $\beta, \quad$ IL-6, macrophage inflammatory protein (MIP)-1 $\alpha$, IL-10) release from alveolar macrophages of a group of a) six non-severe and b) six severe asthmatics by p38 mitogen-activated protein kinase inhibitor (SD282; $10^{-7} \mathrm{M}$; $\square$ ), dexamethasone $\left(10^{-6} \mathrm{M} ; \mathbf{\square}\right)$, or both $(\mathbf{\square})$. *: $\mathrm{p}<0.05$.

With dexamethasone $\left(10^{-8} \mathrm{M}\right)$, the inhibitory effect was also improved in the presence of GW-A $(\mathrm{p}<0.001$, one-way ANOVA), with maximal suppression with GW-A $\left(10^{-6} \mathrm{M}\right)$ being $73.4 \pm 4.5 \%$ compared with $31.3 \pm 3.8 \%$ with dexamethasone alone. Similar effects were observed with dexamethasone at a concentration of $10^{-9} \mathrm{M}$, in combination with GW-A (fig. 5a). We obtained similar results when examining the release of IL-6 (fig. 6).

\section{DISCUSSION}

We have previously shown impaired corticosteroid sensitivity in AMs and PBMCs from patients with severe asthma and increased activation of p38 MAPK in AMs of severe asthmatics $[2,3]$. We now demonstrate that a low concentration of a p38 MAPK inhibitor, SD282, that had little effect on IL-1 $\beta$, IL-6 and MIP- $1 \alpha$ release, improved the inhibitory activity of dexamethasone in AMs from severe asthma patients. This effect was not observed in PBMCs from patients with severe asthma because the concentration of SD282 chosen had a major suppressive effect on cytokine release. To investigate more closely any interaction between p38 MAPK inhibition and corticosteroids, we studied a wider range of concentrations of another p38 MAPK inhibitor, GW-A, and showed an enhancement of the suppressive effects of dexamethasone in PBMCs from patients with severe asthma at concentrations of GW-A that had no
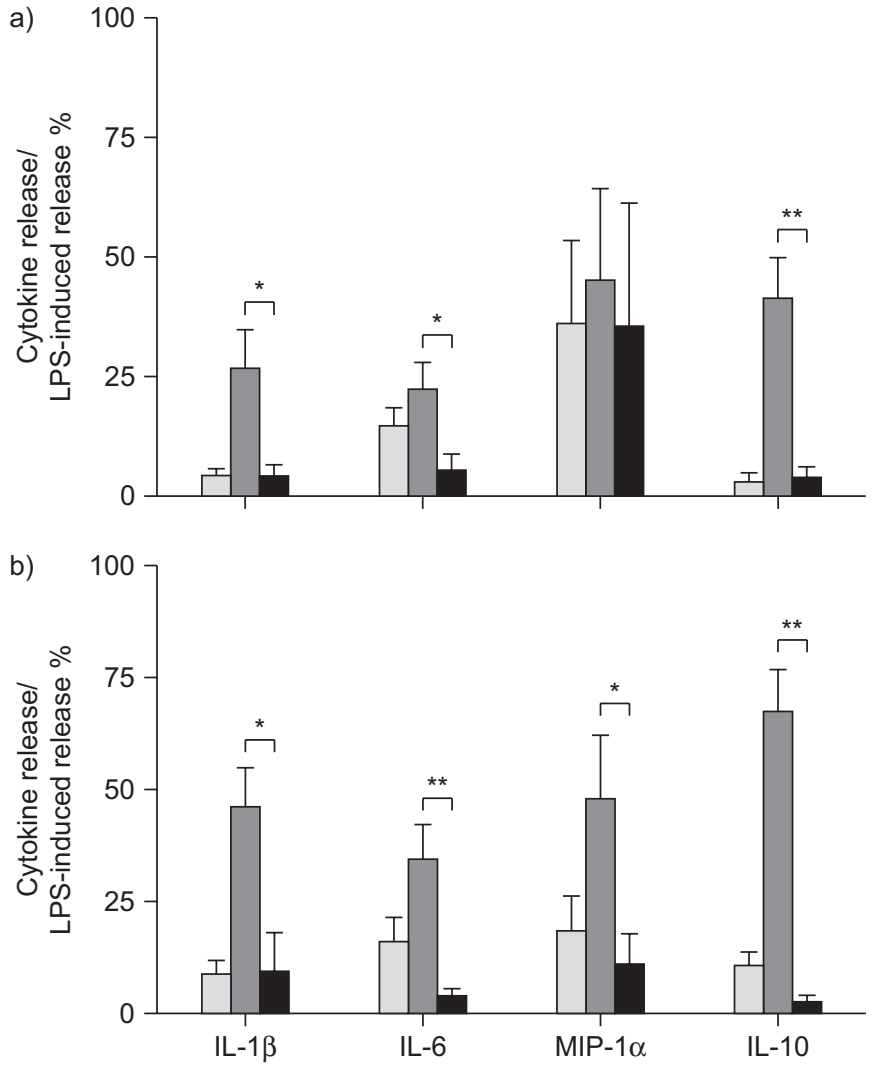

FIGURE 3. Inhibition of lipopolysaccharide (LPS)-induced cytokine (interleukin (IL)-1 $1 \beta$, IL-6, macrophage inflammatory protein (MIP)-1 $\alpha$ ) release from periphera blood mononuclear cells of a group of a) six non-severe and b) six severe asthmatics by p38 mitogen-activated protein kinase inhibitor (SD282; $10^{-7} \mathrm{M} ; \quad$ ), dexamethasone $\left(10^{-6} \mathrm{M} ; \mathbf{\square}\right)$, or both $(\mathbf{\square}){ }^{*}$ : $\mathrm{p}<0.05 ;{ }^{* *}: \mathrm{p}<0.01$.

effect on IL-8 release. For example, the maximal suppression of IL-8 release obtained with the highest concentration of dexamethasone $\left(10^{-6} \mathrm{M}\right)$, was also achieved with a 100 -fold reduction in dexamethasone concentration $\left(10^{-8} \mathrm{M}\right)$ with addition of GW-A $\left(10^{-9} \mathrm{M}\right)$. The enhancement in the inhibitory effects of dexamethasone appears to be synergistic because the suppression by dexamethasone $\left(10^{-8} \mathrm{M}\right)$ and by GW-A $\left(10^{-9} \mathrm{M}\right)$ alone were 28 and $3 \%$, respectively, whereas the suppression observed when added in combination was increased to $59 \%$. We also found similar effects with IL-6 release.

It is of interest that there was also additivity in the effects of SD282 and dexamethasone in AMs from patients with nonsevere asthma in suppressing the release of IL-1 $1 \beta$, IL- 6 and MIP- $1 \alpha$, albeit to a lesser extent, even though the degree of inhibition by dexamethasone alone was substantial. However, this was not seen with IL-10 release in AMs from non-severe asthma patients, but was present in AMs from severe asthma patients. Therefore, overcoming corticosteroid insensitivity by using p38 MAPK inhibitors can be demonstrated in severe asthmatics. Our data are supported by a recent study that reported that a p38 MAPK inhibitor in combination with dexamethasone caused a greater suppression of gene expression induced by LPS in monocyte-derived macrophages or AMs [10]. 


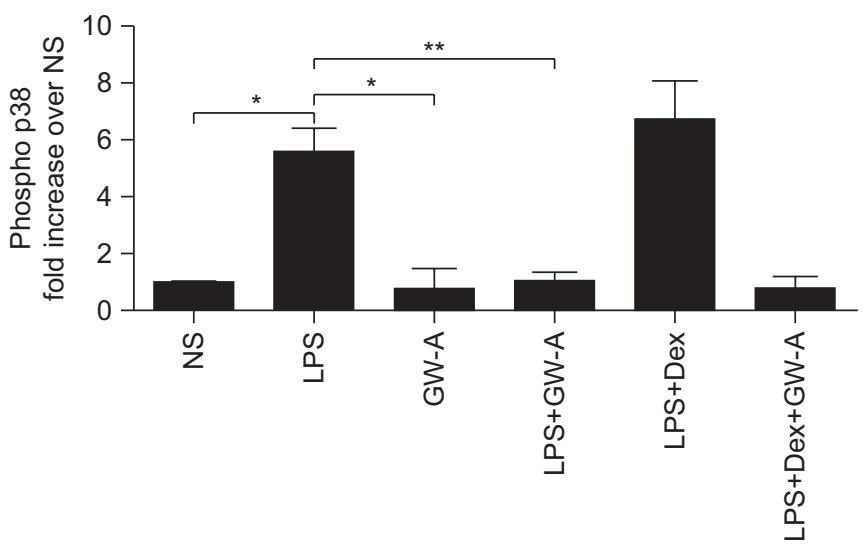

FIGURE 4. Inhibition of lipopolysaccharide (LPS)-induced p38 phosphorylation in peripheral blood mononuclear cells from severe asthmatic patients $(n=3)$ by the p38 inhibitor, GW-A $\left(553 ; 10^{-9} \mathrm{M}\right)$ in the presence or absence of dexamethasone (Dex; $10^{-8} \mathrm{M}$ ). NS: not stimulated. ${ }^{*}$ : $p<0.05$; ${ }^{*}: \mathrm{p}<0.01$.

The p38 MAPK inhibitor, SD282, is an indole-5-carboxamide selective p38 $\alpha$ MAPK inhibitor demonstrating a 14.3-fold greater potency for $\mathrm{p} 38 \alpha$ compared with $\mathrm{p} 38 \beta[8,9]$. No detectable effect on other closely related kinases such as p38 , p38 $\gamma$, jun-N-terminal kinase and p38 activating kinases at concentrations up to $50 \mathrm{mM}$ in human PBMCs has been observed [8] and, therefore, these effects are likely to result from the selective inhibition of the $\mathrm{p} 38 \alpha \mathrm{MAPK}$ isoform. GW-A is another p38 MAPK inhibitor that is currently in clinical development [11]. We have shown that concentrations of GW-A $\left(10^{-9}\right.$ and $\left.10^{-10} \mathrm{M}\right)$ that had no effect on cytokine release, still demonstrated significant inhibition of p38 MAPK activity in peripheral blood monocytes exposed to LPS. This suggests that p38 MAPK activation is associated with corticosteroid insensitivity. Phosphorylation of p38 MAPK was measured as an indicator of the efficacy of GW-A, rather than one of its downstream targets, based on studies which have demonstrated that p38 inhibitors can prevent phosphorylation of p38 $\alpha$ in vitro $[12,13]$. Additional studies have demonstrated that $\mathrm{p} 38 \alpha$ can auto-phosphorylate [14] and trans-phosphorylate [19].
Finally, SB203508, another p38 MAPK inhibitor related to GW-A, inhibits the enzymatic activity of both activated and unactivated forms of $\mathrm{p} 38 \alpha$ [15].

A role for p38 MAPK activation in severe asthma has been suggested by the observation that macrophages from such patients demonstrate increased p38 MAPK activation when exposed to LPS [2]. Previous studies have indicated a role for p38 MAPK activation in murine asthma models. Thus, in a chronic allergen model, suppression of p38 $\alpha$ MAPK by an inhibitor or by antisense oligonucleotide-attenuated ovalbumininduced bronchial hyperreactivity, eosinophilia, goblet cell hyperplasia, airway smooth muscle hypertrophy and bronchial hyperresponsiveness, through a reduction of T-helper cell type 2 cytokines associated with allergic inflammation [16, 17]. Another potential effect of p38 inhibition is the reversal of corticosteroid insensitivity that is present in severe asthma [3] We have previously demonstrated that IL-2- and IL-4-mediated corticosteroid insensitivity of peripheral blood mononuclear cells can be reversed by inhibition of p38 MAPK activity [6]. This insensitivity was reflected by a reduction in corticosteroid ligand binding affinity due to phosphorylation of the glucocorticoid receptor, that could be reversed by a p38 MAPK inhibitor [6], or by an indirect effect on the ligand binding domain of glucocorticoid receptor [18]. Alternatively, p38 MAPK activation may also lead to phosphorylation and phosphoacetylation of histones in the promoter regions of NF$\kappa \mathrm{B}$ dependent genes, such as those activated by LPS, resulting in enhanced recruitment of the transcription factor NF- $\mathrm{KB}[19,20]$ This is consistent with previous observations that histone deacetylase activity is reduced in PBMCs and AMs of asthmatic patients $[3,21]$.

p38 MAPK activation may be involved in the stabilisation and increased translation of pro-inflammatory cytokine mRNA, dependent on the conserved AU-rich elements in the 3'-UTR region [22]. Of the pro-inflammatory cytokine mRNAs that can be stabilised by p38 MAPK activation in monocyte and macrophage cell lines, IL-1 $\beta$, IL-6, IL-8, and MIP-1 $\alpha$ [23-25] are the same cytokines that were less inhibited by dexamethasone in AMs from severe asthma patients, and where the extent
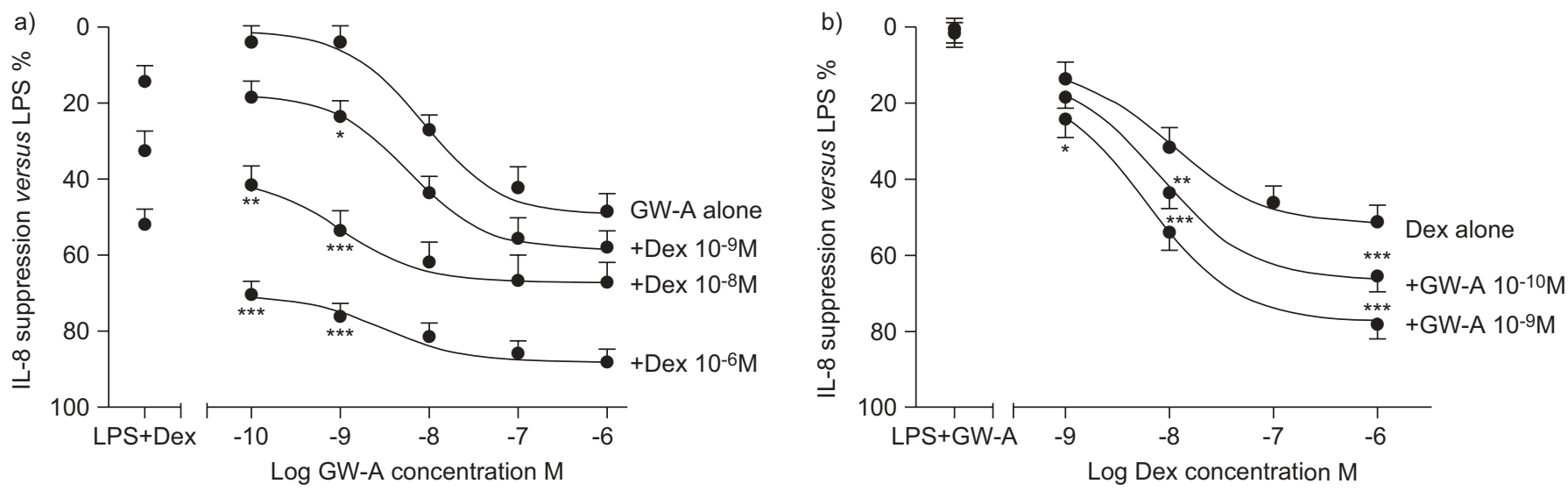

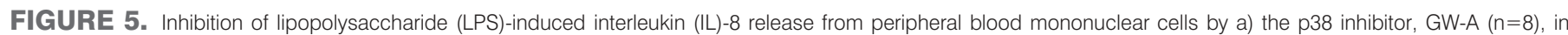

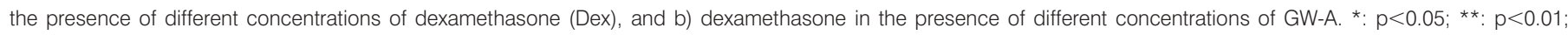
$\star * *: p<0.001$, compared with dexamethasone, at the given concentration, alone. 

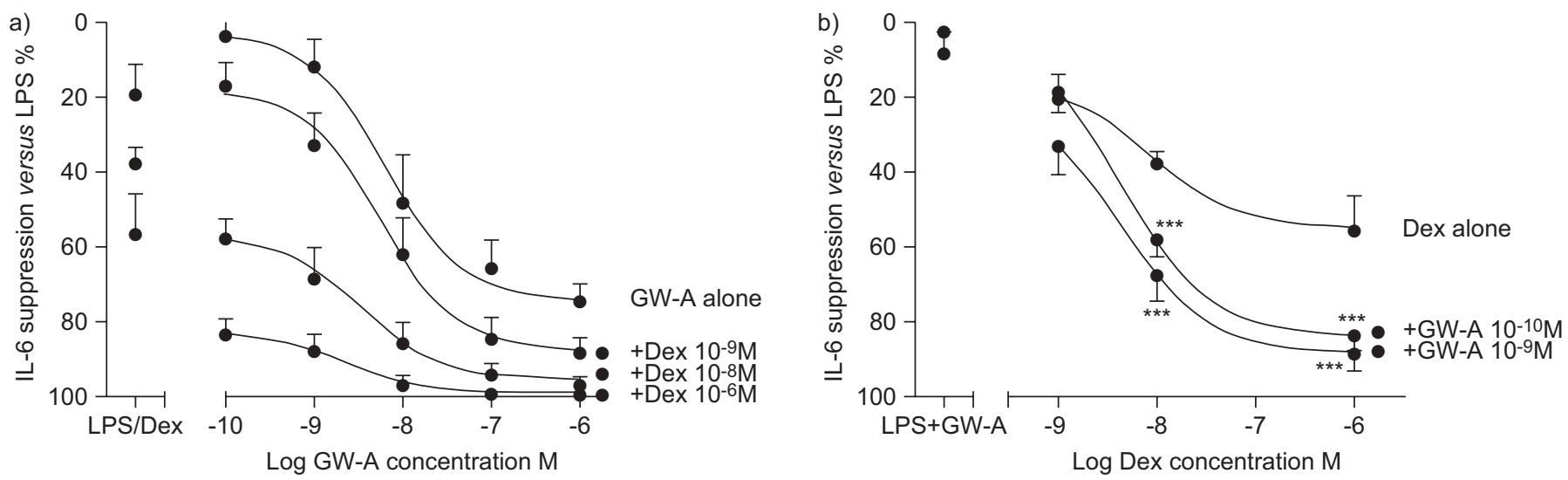

FIGURE 6. Inhibition of lipopolysaccharide (LPS)-induced interleukin (IL)-6 release from peripheral blood mononuclear cells by a) the p38 inhibitor, GW-A ( $\mathrm{n}=5$ ), in the presence of different concentrations of dexamethasone (Dex), and b) dexamethasone in the presence of different concentrations of GW-A. ${ }^{* * *}$ : $p<0.001$, compared with dexamethasone, at the given concentration, alone.

of inhibition by dexamethasone was correlated with the degree of p38 MAPK activation [3]. These potential downstream effects of $\mathrm{p} 38 \mathrm{MAPK}$ do not lead to enhanced release of cytokines from the AMs but to a reduction in the effectiveness of corticosteroids. Although this study has focused on p38 MAPK activity in this study, activation of other members of the MAPK family such as c-jun $\mathrm{N}$-terminal kinase and extracellular signalregulated kinase ERK $[26,27]$ have also been implicated in corticosteroid insensitivity. Whether there are interactions between the parallel downstream pathways, to influence corticosteroid sensitivity, deserves further investigation. In previous studies, we have also shown the reduced induction of MAPK phosphatase-1 by dexamethasone in AMs from patients with severe asthma [2]. This suggests another potential mechanism for increased activation of p38 MAPK activity.

The effect of dexamethasone in inhibiting IL-10 release induced by LPS from AMs and PBMCs may seem contradictory when induction of IL-10 release by corticosteroids has been shown in ex vivo studies of AMs or blood monocytes from patients who have been treated with either inhaled corticosteroids [30] or systemic methylprednisolone [31]. However, direct incubation of monocytes or AMs stimulated by LPS with deaxmethasone led to an inhibition of IL-10 as we [2,3] and others [31] have shown. p38 MAPK inhibition also reduced IL-10 release from PBMCs or AMs, as confirmed recently in monocytes [32]. We found that the combination of dexamethasone and GW-A caused an increase in inhibition of IL-10 release, particularly in PBMCs and AMs from patients with severe asthma.

Patients with severe asthma need effective new medications that will improve their asthma control. Our study points to a novel approach to the treatment of severe asthma. A p38 MAPK inhibitor may be used as an anti-inflammatory agent and has been shown to be effective in this way in asthma models [16, 17]. We have used this inhibitor to demonstrate its capacity to reverse corticosteroid insensitivity. Immunosuppressive drugs, such as cyclosporin A and methotrexate have been administered in patients with steroid-dependent asthma to lower maintenance oral corticosteroid dosage, while allowing the control of asthma to remain unchanged $[28,29]$, but these drugs have not proven to be useful. A p38 MAPK inhibitor could be effective in reversing corticosteroid insensitivity at lower doses than those needed to inhibit inflammation with a lesser risk of side-effects, but will need to be used concomitantly with corticosteroids.

\section{SUPPORT STATEMENT}

This work was partly supported by NIH RO-1 HL-69155 from the National Institutes of Health, Bethesda, MD, USA and Medical Research Council UK grant G0700900.

\section{STATEMENT OF INTEREST}

Statements of interest for M. Johnson and K.F. Chung can be found at www.erj.ersjournals.com/misc/statements.dtl

\section{ACKNOWLEDGEMENTS}

We thank S. Meah (Imperial College and Royal Brompton and Harefield NHS Trust Hospital, London, UK) for recruitment of patients and for help with the bronchoscopic procedures. We thank Scios Inc, Freemont, CA, USA for provision of SD282 and GlaxoSmithKline, Stevenage, UK, for the supply of GW-A.

\section{REFERENCES}

1 Moore WC, Bleecker ER, Curran-Everett D, et al. Characterization of the severe asthma phenotype by the National Heart, Lung, and Blood Institute's Severe Asthma Research Program. J Allergy Clin Immunol 2007; 119: 405-413.

2 Bhavsar P, Hew M, Khorasani N, et al. Relative corticosteroid insensitivity of alveolar macrophages in severe asthma compared with non-severe asthma. Thorax 2008; 63: 784-790.

3 Hew M, Bhavsar P, Torrego A, et al. Relative corticosteroid insensitivity of peripheral blood mononuclear cells in severe asthma. Am J Respir Crit Care Med 2006; 174: 134-141.

4 Adcock IM, Ford PA, Bhavsar P, et al. Steroid resistance in asthma: mechanisms and treatment options. Curr Allergy Asthma Rep 2008; 8: 171-178.

5 Adcock IM, Chung KF, Caramori G, et al. Kinase inhibitors and airway inflammation. Eur J Pharmacol 2006; 533: 118-132.

6 Irusen E, Matthews JG, Takahashi A, et al. p38 Mitogen-activated protein kinase-induced glucocorticoid receptor phosphorylation reduces its activity: role in steroid-insensitive asthma. J Allergy Clin Immunol 2002; 109: 649-657.

7 Proceedings of the ATS Workshop on Refractory Asthma. Current understanding, recommendations, and unanswered questions. Am J Respir Crit Care Med 2000; 162: 2341-2351. 
8 Lim MY, Wang H, Kapoun AM, et al. p38 Inhibition attenuates the pro-inflammatory response to C-reactive protein by human peripheral blood mononuclear cells. J Mol Cell Cardiol 2004; 37: 1111-1114.

9 Sweitzer SM, Medicherla S, Almirez R, et al. Antinociceptive action of a p38 $\alpha$ MAPK inhibitor, SD-282, in a diabetic neuropathy model. Pain 2004; 109: 409-419.

10 Kent LM, Smyth LJC, Plumb J, et al. Inhibition of lipopolysaccharide-stimulated chronic obstructive pulmonary disease macrophage inflammatory gene expression by dexamethasone and the p38 mitogen-activated protein kinase inhibitor $\mathrm{N}$ cyano-N'-(2-\{[8-(2,6-difluorophenyl)-4-(4-fluoro-2-methylphenyl)-7oxo-7,8-dihydropyrido[2,3-d] pyrimidin-2-yl]amino\}ethyl)guanidine (SB706504). J Pharmacol Exp Ther 2009; 328: 458-468.

11 Margutti S, Laufer SA. Are MAP kinases drug targets? Yes, but difficult ones. ChemMedChem 2007; 2: 1116-1140.

12 Galan A, Garcia-Bermejo ML, Troyano A, et al. Stimulation of p38 mitogen-activated protein kinase is an early regulatory event for the cadmium-induced apoptosis in human promonocytic cells. J Biol Chem 2000; 275: 11418-11424.

13 Matsuguchi T, Musikacharoen T, Ogawa T, et al. Gene expressions of Toll-like receptor 2, but not Toll-like receptor 4, is induced by LPS and inflammatory cytokines in mouse macrophages. J Immunol 2000; 165: 5767-5772.

14 Ge B, Gram H, Di Padova F, et al. MAPKK-independent activation of p38 $\alpha$ mediated by TAB1-dependent autophosphorylation of p38 $\alpha$. Science 2002; 295: 1291-1294.

15 Frantz B, Klatt $\mathrm{T}$, Pang $\mathrm{M}$, et al. The activation state of p38 mitogen-activated protein kinase determines the efficiency of ATP competition for pyridinylimidazole inhibitor binding. Biochemistry 1998; 37: 13846-13853.

16 Duan W, Chan JH, McKay K, et al. Inhaled p38 $\alpha$ mitogen-activated protein kinase antisense oligonucleotide attenuates asthma in mice. Am J Respir Crit Care Med 2005; 171: 571-578.

17 Nath P, Leung SY, Williams A, et al. Importance of p38 mitogenactivated protein kinase pathway in allergic airway remodelling and bronchial hyperresponsiveness. Eur J Pharmacol 2006; 544: 160-167.

18 Szatmary Z, Garabedian MJ, Vilcek J. Inhibition of glucocorticoid receptor-mediated transcriptional activation by p38 mitogenactivated protein (MAP) kinase. J Biol Chem 2004; 279: 43708-43715.

19 Koch A, Giembycz M, Ito K, et al. Mitogen-activated protein kinase modulation of nuclear factor- $\mathrm{kB}$-induced granulocyte macrophagecolony-stimulating factor release from human alveolar macrophages. Am J Respir Cell Mol Biol 2004; 30: 342-349.
20 Saccani S, Pantano S, Natoli G. p38-Dependent marking of inflammatory genes for increased NF- $\mathrm{BB}$ recruitment. Nat Immunol 2002; 3: 69-75.

21 Cosio BG, Mann B, Ito K, et al. Histone acetylase and deacetylase activity in alveolar macrophages and blood mononocytes in asthma. Am J Respir Crit Care Med 2004; 170: 141-147.

22 Dean JL, Sully G, Clark AR, et al. The involvement of AU-rich element-binding proteins in p38 mitogen-activated protein kinase pathway-mediated mRNA stabilisation. Cell Signal 2004; 16: $1113-1121$.

23 Sirenko OI, Lofquist AK, DeMaria CT, et al. Adhesion-dependent regulation of an $\mathrm{A}+\mathrm{U}-$ rich element-binding activity associated with AUF1. Mol Cell Biol 1997; 17: 3898-3906.

24 Wang SW, Pawlowski J, Wathen ST, et al. Cytokine mRNA decay is accelerated by an inhibitor of p38-mitogen-activated protein kinase. Inflamm Res 1999; 48: 533-538.

25 Tebo J, Der S, Frevel M, et al. Heterogeneity in control of mRNA stability by AU-rich elements. J Biol Chem 2003; 278: 12085-12093.

26 Sousa AR, Lane SJ, Soh C, et al. In vivo resistance to corticosteroids in bronchial asthma is associated with enhanced phosyphorylation of JUN N-terminal kinase and failure of prednisolone to inhibit JUN N-terminal kinase phosphorylation. J Allergy Clin Immunol 1999; 104: 565-574

27 Tsitoura DC, Rothman PB. Enhancement of MEK/ERK signaling promotes glucocorticoid resistance in CD4+ T cells. J Clin Invest 2004; 113: 619-627.

28 Shiner RJ, Nunn AJ, Chung KF, et al. Randomised, double-blind, placebo-controlled trial of methotrexate in steroid-dependent asthma. Lancet 1990; 336: 137-140.

29 Lock SH, Kay AB, Barnes NC. Double-blind, placebo-controlled study of cyclosporin A as a corticosteroid-sparing agent in corticosteroid-dependent asthma, Am J Respir Crit Care Med 1996; 153: 509-514.

30 John M, Lim S, Seybold J, et al. Inhaled corticosteroids increase interleukin-10 but reduce macrophage inflammatory protein- $1 \alpha$, granulocyte-macrophage colony-stimulating factor, and interferon- $\gamma$ release from alveolar macrophages in asthma. Am J Respir Crit Care Med 1998; 157: 256-262.

31 Gayo A, Mozo L, Suárez A, et al. Glucocorticoids increase IL-10 expression in multiple sclerosis patients with acute relapse. J Neuroimmunol 1998; 85: 122-130.

32 Dobreva ZG, Miteva LD, Stanilova SA. The inhibition of JNK and p38 MAPKs downregulates IL-10 and differentially affects c-Jun gene expression in human monocytes. Immunopharmacol Immunotoxicol 2009; 31: 195-201. 